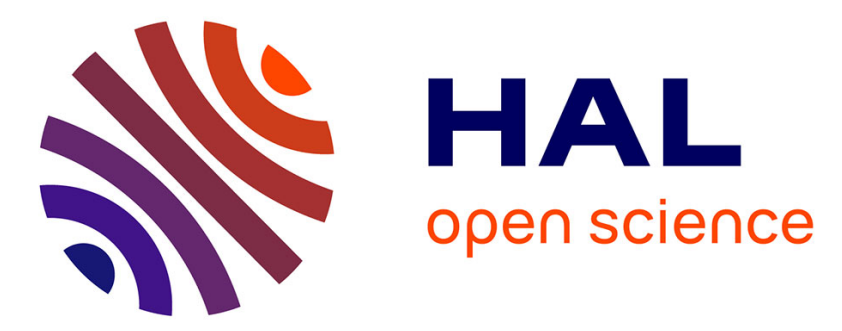

\title{
Small-angle X-ray scattering studies on the polydispersity of iron micelles in ferritin
}

\author{
P. Zipper, M. Kriechbaum, H. Durchschlag
}

\section{To cite this version:}

P. Zipper, M. Kriechbaum, H. Durchschlag. Small-angle X-ray scattering studies on the polydispersity of iron micelles in ferritin. Journal de Physique IV Proceedings, 1993, 03 (C8), pp.C8-245-C8-248. 10.1051/jp4:1993847 . jpa-00252278

\section{HAL Id: jpa-00252278 https://hal.science/jpa-00252278}

Submitted on 1 Jan 1993

HAL is a multi-disciplinary open access archive for the deposit and dissemination of scientific research documents, whether they are published or not. The documents may come from teaching and research institutions in France or abroad, or from public or private research centers.
L'archive ouverte pluridisciplinaire HAL, est destinée au dépôt et à la diffusion de documents scientifiques de niveau recherche, publiés ou non, émanant des établissements d'enseignement et de recherche français ou étrangers, des laboratoires publics ou privés. 


\title{
Small-angle X-ray scattering studies on the polydispersity of iron micelles in ferritin
}

\author{
P. ZIPPER, M. KRIECHBAUM* and H. DURCHSCHLAG ${ }^{* *}$
}

Institute of Physical Chemistry, University of Graz, Heinrichstrasse 28, 8010 Graz, Austria

"Institute of Biophysics and X-Ray Structure Research, Austrian Academy of Sciences, Steyrergasse 17, 8010 Graz, Austria

${ }_{* *}^{*}$ Institute of Biophysics and Physical Biochemistry, University of Regensburg, Universitätsstrasse 31, 93040 Regensburg, Germany

Small-angle X-ray scattering was applied to study the structure of horse-spleen ferritin and apoferritin as well as of various intermediate states differing in their iron content. The intermediates were produced by partial removal of iron from ferritin or by incorporation of iron into apoferritin. Measurements were performed in dilute buffer and in $66 \%(\mathrm{w} / \mathrm{v})$ sucrose solution. The scattering curves were analysed in terms of radii of gyration, $R_{G}$, distance distribution functions, $p(r)$, and size distribution functions, $D_{v}(R)$. The results reflect characteristic changes of $R_{G}$ and of $p(r)$ upon release or uptake of iron and suggest a bimodal polydisperse size distribution of iron micelles in ferritin. The interpretation of data was paralleled by computer simulations based on various different models.

\section{Introduction}

Ferritin is the major iron-storage protein in mammals. Its 24 subunits form an approximately spherical protein shell which surrounds a core of microcrystalline ferric oxide hydrate. The ferric micelle contains a variable number of iron atoms. Both full ferritin and iron-free apoferritin have already been subject of previous smallangle investigations using $\mathrm{X}$-rays or neutrons (e.g. [1-3]). The present study is primarily concerned with SAXS studies on various intermediate states of horse-spleen ferritin differing in their iron content [4].

\section{Experimental}

Horse-spleen ferritin was purchased from Boehringer, apoferritin was obtained from Sigma. The ferritin intermediates were produced by partial removal of iron from ferritin (by treatment with $\mathrm{Na}_{2} \mathrm{~S}_{2} \mathrm{O}_{4}$ and EDTA) or by incorporation of iron into apoferritin (by treatment with $\left.\left(\mathrm{NH}_{4}\right)_{2} \mathrm{Fe}\left(\mathrm{SO}_{4}\right)_{2}\right)$. The iron content of the intermediates was checked spectrophotometrically.
SAXS measurements were performed in $0.1 \mathrm{M}$ phosphate buffer or in buffered $66 \%(\mathrm{w} / \mathrm{v})$ sucrose solution to match out the scattering of the protein moiety. Particle concentrations ranged from about 50 to about $5 \mathrm{mg} / \mathrm{ml}$. A graphite monochromator was used to eliminate disturbing fluorescence of iron. The scattering data were extrapolated to zero concentration and were then desmeared and evaluated (for theory cf. [5]) in terms of distance distribution functions $p(r)$, (mean) radii of gyration $R_{G}$ (calculated from the second moment of $p(r)$ ), and size distribution functions $D_{v}(R)$ (assuming spherical shape of micelles) by applying the indirect transformation method as implemented in program ITP [6].

\section{Results}

Experiments in buffer revealed pronounced changes of $R_{G}$ values (Table $I$ ) and of $p(r)$ functions (Fig. 1) of particles upon release or uptake of iron. The observed changes clearly reflect alterations in the core and shell structure of the particles, namely a decrease (increase) of scattering mass in the core region by release (incor- 
Table I

Radii of Gyration of Ferritin Samples in Buffer and in Sucrose Solution

\begin{tabular}{|c|c|c|c|c|}
\hline & \multirow[b]{2}{*}{ No. } & \multirow{2}{*}{$\begin{array}{c}\mathrm{Fe} \\
\%(w / w)\end{array}$} & \multicolumn{2}{|r|}{ [nm] } \\
\hline & & & Buffer & Sucrose \\
\hline Ferritin native & 1 & 20 & 3.73 & 2.89 \\
\hline \multirow[t]{4}{*}{ Ferritin treated } & 2 & 18 & 3.82 & 2.88 \\
\hline & 3 & 10 & 4.08 & 2.82 \\
\hline & 4 & 4.5 & 4.67 & 2.75 \\
\hline & 5 & 0.5 & 5.24 & \\
\hline Apoferritin & 6 & 0 & 5.33 & \\
\hline \multirow[t]{2}{*}{ Apoferritin treated } & 7 & 1.5 & 4.86 & 2.66 \\
\hline & 8 & 2.5 & 4.69 & 2.76 \\
\hline \multicolumn{3}{|r|}{ Accuracy } & \pm 0.1 & \pm 0.1 \\
\hline
\end{tabular}

poration) of iron. A characteristic feature of the normalized $p(r)$ functions in Fig. $1 \mathrm{a}$ is the crossing in a single point.
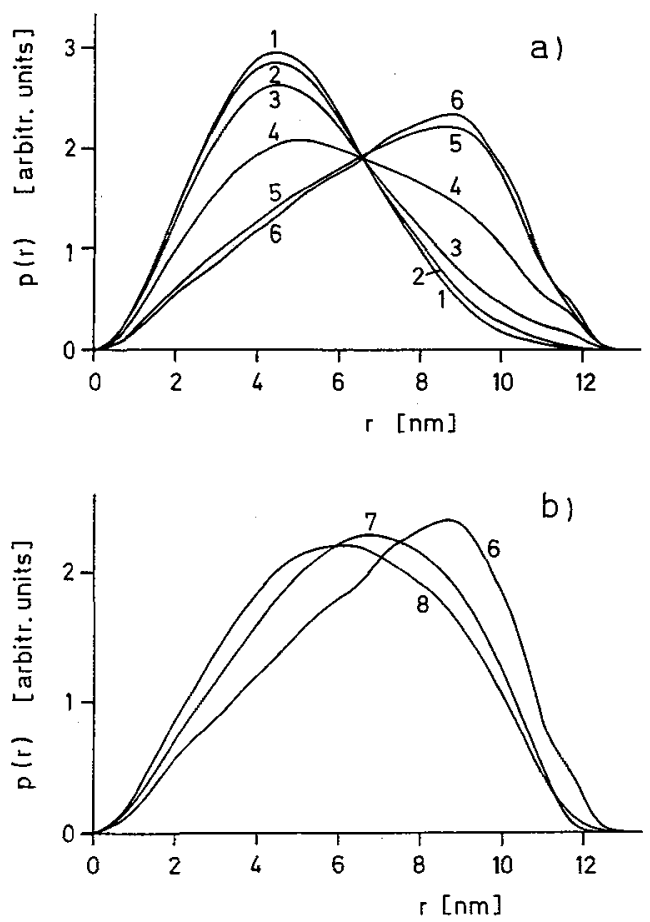

Fig. I: Distance distribution functions $p(r)$ derived from $S A X S$ measurements of untreated and treated ferritin (a) and apoferritin (b) samples in buffer. The numbering of samples is the same as in Table 1. For better comparison the $p(r)$ functions were normalized to the same area (actually the integrals over $p(r)$ decreased with decreasing iron content). All functions correspond to particles of $12.5 \pm 0.5 \mathrm{~nm}$ diameter. In spite of the changes in the shape of the $p(r)$ functions upon release of iron and the shift of the maximum from $4.5 \mathrm{~nm}$ (for native ferritin) to $8.7 \mathrm{~nm}$ (for apoferritin), the $p(r)$ functions cross each other in virtually the same point.

Less pronounced changes of $R_{G}$ and in the shape of $\mathrm{p}(\mathrm{r})$ were derived from the data measured in sucrose solution (Tab. I and Fig. 2). In this solvent the ferric cores alone contribute to SAXS. The observed behavior of $R_{g}$ and $p(r)$ therefore suggests that the average size of the ferric micelles does not decrease very much upon the release of iron from ferritin. The evaluation of the sucrose data in terms of $D_{v}(R)$ functions of the ferric micelles yielded a bimodal polydisperse distribution of micellar size (Fig. 3a). This kind of distribution was found to be retained during the release of iron from ferritin, 

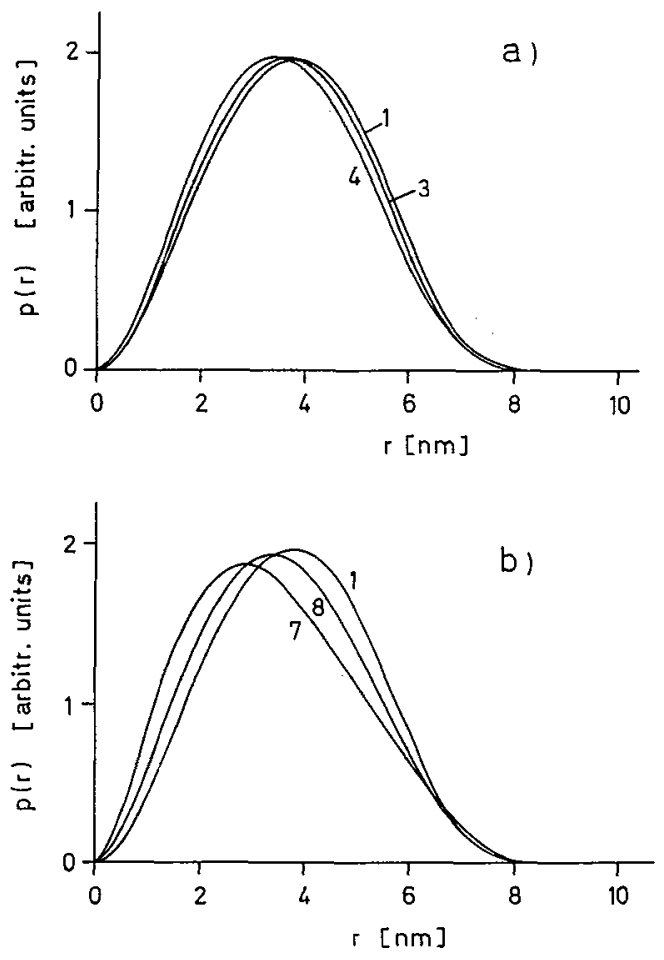

Fig. 2: Normalized distance distribution functions of untreated and treated samples in $66 \%$ buffered sucrose solution. Since the protein moiety is matched out in this solvent, the diameters of $8.0 \pm 0.2 \mathrm{~nm}$ correspond to the maximum dimension of the ferric micelles.

its features varying in a characteristic fashion with the iron content. This behavior of $D_{v}(R)$ functions was interpreted to reflect the presence of two types of ferric micelles differing in size and presumably also in the rate of iron release. Bimodal $D_{v}(R)$ functions were also obtained upon incorporation of iron into apoferritin (Fig. $3 b)$.

SAXS measurements performed on different ferritin preparations led to similar results, but the shape of $D_{V}(R)$ functions was found to vary for different preparations.

The interpretation of results was paralleled by various computer simulations. Scattering curves of models were calculated analytically or numerically, averaged (if necessary) under appropriate weighting [4], and then Fourier transformed to yield $p(r)$ functions. The models were chosen appropriately in order to fit the experimental $R_{G}$ values of the various samples in buffer.

Models based on the assumption of two or three kinds of coexisting particles (apoferritin and one or two ferritin species differing in micellar size) were found to simulate the experimentally observed changes in the $p(r)$ functions upon iron release very well ("model I"; cf. Fig. 4 with Fig. 1a). On the other hand, alternative models assuming different types of isotropic uniform degradation of spherical micelles turned out to be incompatible with the experimental $p(r)$ functions (cf. Fig. 5).
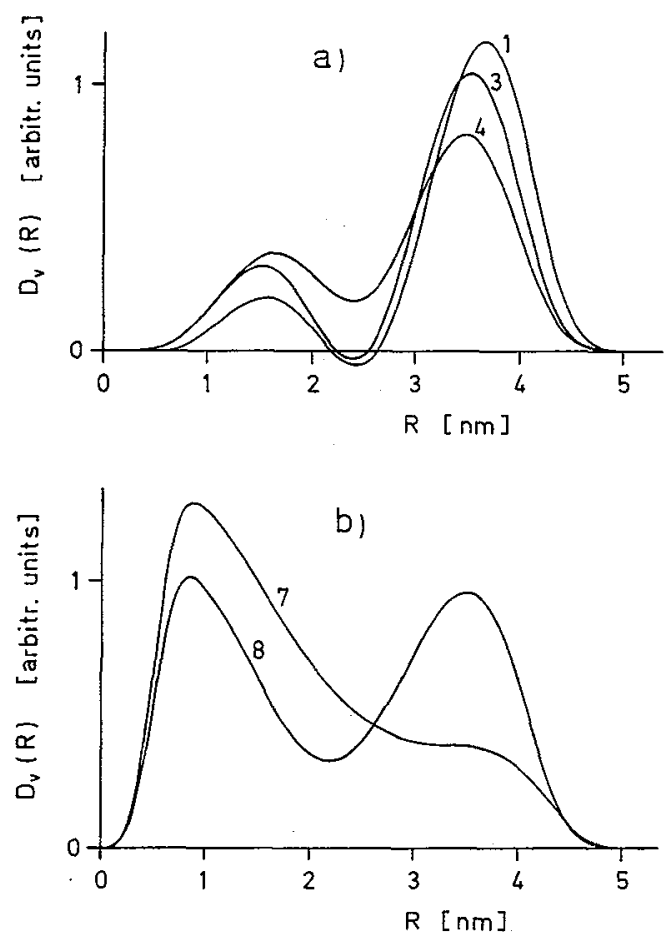

Fig. 3: Size distribution functions $D_{V}(R)$ derived from SAXS measurements of untreated and treated samples in $66 \%$ sucrose solution. $D_{V}(R)$ represents the distribution of volumes of spherical particles whose size is expressed by their radius $R$.

Among models assuming different types of anisotropic degradation of initially spherical micelles the one modelling the iron cores of 
intermediates by spherical segments ("model II") was found to fit best with respect to the crossing behavior of normalized $p(r)$ functions. On the whole, however, the fit of this model was worse than that for model I shown in Fig. 4. Alternative models which retained a bridge across the entire cavity (cf. [1]) gave even poorer fits to the experimental $p(r)$ functions of ferritin in buffer.

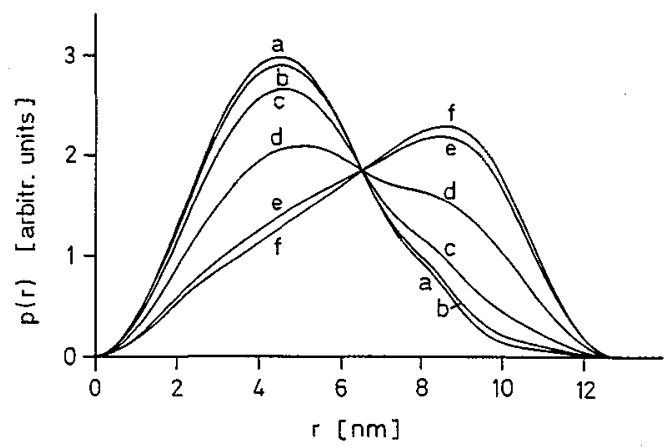

Fig. 4: Normalized distance distribution functions obtained from computer simulations of iron release from ferritin. The underlying model assumes the coexistence of two kinds of particles: ferritin particles with large (diameter 7.5 nm) micelles and apoferritin, in varying relative amounts ("model $\left.I^{\prime \prime}\right)$. The curves shown correspond to mean radii of gyration of $3.73 \mathrm{~nm}$ (a), $3.82 \mathrm{~nm}$ (b), $4.08 \mathrm{~nm}$ (c), $4.67 \mathrm{~nm}$ (d), 5.24 $\mathrm{nm}(\mathrm{e})$, and $5.33 \mathrm{~nm}(f)$. Similar $p(r)$ functions were obtained for models assuming the simultaneous presence of ferritin particles with large and small micelles, respectively, and of apoferritin.

\section{Discussion}

Our SAXS experiments on ferritin intermediates revealed some new features of the scattering behavior of ferritin: the crossing of normalized $p(r)$ functions (of ferritin in buffer) in a single point and the bimodal polydisperse size distribution of ferric micelles. A variety of models was compared with the experimental results. Only a few of them were able to simulate the singlepoint crossing of $p(r)$ functions exactly. The common feature of these models is that they re- present mixtures of only a few different species of particles in varying relative amounts. Since models like model I appear too much simplified we may conclude from the relatively good fit of model II that the scattering behavior of the ferritin samples investigated can be interpreted best by assuming a combination of models I and II, i.e. the coexistence of full and (nearly) empty ferritin particles and of intermediates similar to those in model II.

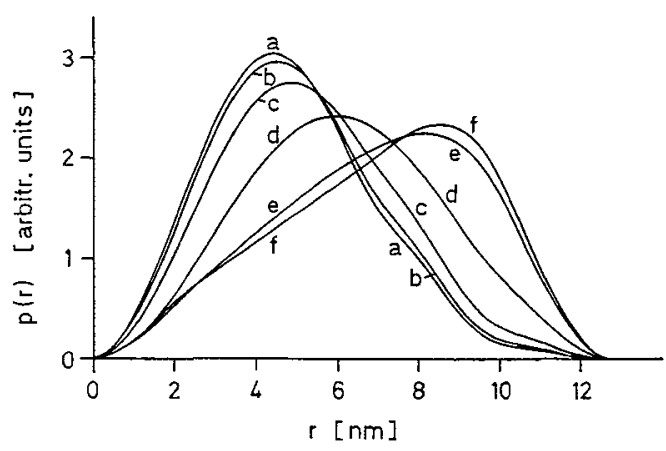

Fig. 5: Normalized distance distribution functions obtained from computer simulations of iron release from ferritin. The underlying model assumes a uniform decrease of electrondensity of initially identical large micelles (diameter 7.5 $n m$ ), at constant micellar size. The radii of gyration are the same as in Fig. 4. Alternative models assuming a uniform decrease of size of initially monosized micelles, at constant electron density, were also found to misfit the experimental $p(r)$ functions.

\section{References}

[1] Fischbach FA, Anderegg JW (1965) J Mol Biol 14:458-473

[2] Bielig HJ, Kratky O, Rohns G, Wawra, H (1966) Biochim Biophys Acta 112:110-118

[3] Stuhrmann HB, Haas J, Ibel K, Koch MHJ, Crichton RR (1976) J Mol Biol 100:399-413

[4] Kriechbaum M (1986) Thesis. Univ. Graz [5] Glatter O (1982) In: Glatter O, Kratky O (eds) Small Angle X-ray Scattering. Academic Press, London, pp. 119-165

[6] Glatter O (1977) J Appl Cryst 10:415-421; (1980) J Appl Cryst 13:7-11 